\title{
RESPON PERTUMBUHAN DAN HASIL PADI GOGO TERHADAP PEMBERIAN BEBERAPA DOSIS KOMPOS SAMPAH KOTA
}

\author{
Yusnaweti * \\ * ) Fakultas Pertanian Universitas Muhammadiyah Sumatera Barat.Tel 0751-4851002 \\ Weti21@yahoo.com \\ HP : 08126756305
}

\begin{abstract}
Abstrak
Penelitian "Respon Pertumbuhan Dan Hasil Padi Gogo Terhadap Beberapa Dosis Kompos Sampah Kota " adalah percobaan lapangan dan laboratorium Fakultas Pertanian Universitas Muhammadiyah Sumatera Barat. Tujuan penelitian untuk mendapatkan dosis kompos sampah kota yang tepat untuk ;pertumbuhan dan hasil padi gogo. Rancangan yang digunakan adalah Rancangan Acak Kelompok (RAK), dengan 5 taraf dan 4 ulangan yaitu : dosis kompos sampah kota adalah $0,5,10$, 15 dan $20 \mathrm{t} / \mathrm{ha}$. Data pengamatan dianalis secara statistika dengan uji $\mathrm{F}$ pada taraf nyata $5 \%$. Hasil peneltian memperlihatkan dosis $20 \mathrm{t} / \mathrm{ha}$ dapat memberikan hasil yang terbaik untuk pertumbuhan tanaman padi gogo.
\end{abstract}

Kata kunci: Kompos sampah kota dan padi gogo

(C) 2017 Yusnaweti Yusnaweti

\section{ON GROWTH RESPON AND RESULTS OF UPLAND RICE DUE TO THE ALLOTMENT OF SOME A DOSE OF COMPOST GARBAGE CITY}

\begin{abstract}
The research " On Growth Response and the Results of Upland Rice due to the Allotment of Some a Dose of Compost Garbage City ". On the field and laboratory of Agriculture Faculty, Muhammadiyah University of West Sumatra. Research purposes, to get a dose of compost garbage city which is proper for upland rice . This is a experiment in Completely Random Block Design, with 5 level and 4 replication of dose of compost bamboo leaves $0,5,10,15$ and $20 \mathrm{t} / \mathrm{ha}$. Data observation analyzed in statistic by test $f$ the first real 5 percent. The results showed research for growth and upland rice the results of a dose $20 \mathrm{t} /$ ha give the best results for growth and the results of upland rice.
\end{abstract}

Key words : Compost garbage city ; upland rice

\section{PENDAHULUAN}

Indonesia saat ini menghadapi masalah pangan akibat peningkatan jumlah penduduk yang diikuti banyaknya sawah subur ber irigasi, yang beralih fungsi menjadi kawasan industri dan pemukiman. Selain itu pengaruh bencana alam berupa kemarau panjang atau banjir yang hampir setiap tahun, sehingga untuk memenuhi keperluan nasional pemerintah mengimpor beras mencapai
1.428.505,678 t dengan nilai US\$ 291.422.862 (BPS, 2013a), oleh karena itu tantangan kedepan adalah bagaimana meningkatan hasil padi sawah maupun padi gogo.

BPS (2014) melaporkan bahwa ratarata produktifitas padi gogo di Indonesia baru mencapai $3.66 \mathrm{t}$ ha-1, dengan luas areal panen \pm 1.04 juta ha dan hanya menyumbang $5.01 \%$ terhadap hasil beras nasional. Hasil rata-rata tersebut masih sangat rendah karena padi gogo 
umumnya ditanam ditanah marginal dan menggunakan sistem konvensional (Soeraptoharjo dan Suwarjo, 1988). Salah satu usaha untuk meningkatkan pertumbuhan dan produksi padi gogo dengan pemanfaatan kompos ampas sampah kota.

Tujuan penelitian untuk mendapatkan dosis kompos sampah kota yang terbaik sehingga dapat meningkatkan pertumbuhan dan hasil padi gogo..

\section{BAHAN DAN METODA}

Penelitian ini merupakan percobaan lapangan, bahan-bahan yang digunakan dalam percobaan adalah : Varietas padi gogo Situ bagendit, pupuk Urea, SP-36 dan $\mathrm{KCl}(200 \mathrm{~kg}$ $\mathrm{ha}^{-1}$ Urea, $250 \mathrm{~kg} \mathrm{ha}^{-1} \mathrm{SP}-36$ dan $100 \mathrm{~kg} \mathrm{ha}^{-1}$ $\mathrm{KCl}$. Kompos sampah kota, pemberian kompos sebanyak $0,5,10,15$ dan $20 \mathrm{t} / \mathrm{ha}$ di berikan seminggu sebelum tanam. Pemupukan anorganik di berikan $1 / 2$ dosis urea sedangkan SP 36 dan $\mathrm{KCl}$ seluruhnya, pada saat tanam kemudian $1 / 2$ dosis Urea umur 40 hari. Perawatan dilakukan penyiraman kalau tidak turun hujan. Penyiangan gulma dilakukan secara manual dengan mencabut gulma pada waktu 2 MST dan 6 MST, sedangkan pengendalian hama dan penyakit dilakukan secara bijak

Penelitian menggunakan metoda eksperimen yang digunakan adalah Rancangan Acak Kelompok (RAK) dengan 5 perlakuan dan 4 ulangan. Semua data pengamatan yang diperoleh dianalisis dengan uji $\mathrm{F}$ pada taraf nyata $5 \%$, bila berbeda nyata dilanjutkan dengan Duncan's New Multiple Range Test (DNMRT) pada taraf nyata 5\%.

Pengamatan adalah pengamatan tinggi tanaman, jumlah anakan per rumpun, persentase anakan produktif per rumpun, jumlah malai per rumpun, panjang malai, jumlah gabah per malai, bobot kering gabah per rumpun/petak/ha dan bobot 1000 biji.

\section{HASIL DAN PEMBAHASAN}

a. Tinggi tanaman (cm).

Rata-rata tinggi tanaman padi setelah diuji lanjut DNMRT pada taraf nyata $5 \%$ dapat dilihat pada Tabel 1 .

Tabel 1. Tinggi tanaman padi pada beberapa dosis kompos sampah kota umur 10 MST.

\begin{tabular}{cc}
\hline $\begin{array}{c}\text { Dosis kompos sampah kota } \\
(\mathrm{t} / \mathrm{ha})\end{array}$ & Tinggi Tanaman \\
$(\mathrm{cm})$
\end{tabular}

$\mathrm{KK}=3.51 \%$

Angka-angka pada kolom yang sama tidak diikuti oleh huruf kecil yang sama berbeda tidak nyata pada taraf nyata $5 \%$ menurut DNMRT.

Pada Tabel 1, dapat dilihat bahwa tinggi tanaman padi tidak memperlihatkan perbedaan yang nyata sesamanya baik antara pengaruh berbagai dosis kompos sampah kota. Hal ini diduga tinggi tanaman dipengaruhi sifat genetic dari tanaman itu sendiri. Sesuai dengan pendapat Gadner, Pearce dan Mitchell (1991) bahwa tanaman dipengaruhi oleh genetiknya termasuk tinggi tanaman. Pada penelitian Yusnaweti (2014) pada tanaman padi gogo varietas Danau gaung juga di dapat tinggi yang tidak berbeda nyata ter hadap beberapa jenis Cendawan Mikoriza Arbuskula.

\section{b. Jumlah anakan rumpun-1 (batang).}

Rata-rata jumlah anakan/rumpun tanaman padi gogo setelah diuji lanjut DNMRT pada taraf nyata $5 \%$ dapat dilihat pada Tabel 2 . 
Tabel 2. Jumlah anakan/rumpun tanaman padi pada berbagai dosis kompos sampah kota umur 10 MST.

\begin{tabular}{|c|c|}
\hline Dosis kompos sampah kota (t/ha) & Jumlah anakan /rumpun (batang) \\
\hline 0 & $18.21 \quad \mathrm{a}$ \\
\hline 5 & $19.78 \quad \mathrm{a}$ \\
\hline 10 & $21.15 \quad \mathrm{a}$ \\
\hline 15 & 25.84 \\
\hline 20 & 30.10 \\
\hline
\end{tabular}

$\mathrm{KK}=22.37 \%$

Angka-angka pada kolom yang sama tidak diikuti oleh huruf kecil yang sama berbeda tidak nyata pada taraf nyata $5 \%$ menurut DNMRT.

Pada Tabel 2, dapat dilihat bahwa jumlah anakan per rumpun tanaman padi dosis kompos sampah kota 20 t/ha memperlihatkan jumlah anakan per rumpun tertinggi yaitu 30.10 batang yang berbeda nyata dengan disis kompos 15, 10, 5 dan 0 t/ha. Tetapi antara dosis kompos sampah kota 10, 5 dan 0 t/ha tidak berbeda nyata sesamanya.

Hal ini diduga bahwa pada dosis kompos sampah kota 20 t/ha mempunyai unsur hara lebih banyak tersedia dan mencukupi untuk pertumbuhan tanaman. Hasil penelitian Agustamar (2007) kadar hara kompos tithonia $(\mathrm{B} . \mathrm{O}=50.49 \%, \mathrm{C}-\mathrm{org}=29.28 \%$, $\mathrm{C} / \mathrm{N}=9.27, \mathrm{~N}=3.16 \%, \mathrm{P}=0.73 \%, \mathrm{~K}=3.97$ $\%$ dan kadar air $=17.91 \%$ ) sedangkan kompos Sapi (B.O = 35.45\%, C-org $=20.56 \%, \mathrm{C} / \mathrm{N}=$ 13.39, $\mathrm{N}=1.54 \%, \mathrm{P}=0.43 \%, \mathrm{~K}=1.57 \%$ dan kadar air $=37.06 \%$ ). Hara yang cukup akan meningkatkan fotosintesis yang akan menghasilkan jumlah anakan per rumpun yang lebih banyak.

\section{c. Persentase anakan produktif rumpun ${ }^{-1}$ (\%).}

Rata-rata perentase anakan produktif per rumpun padi gogo setelah diuji lanjut DNMRT pada taraf nyata $5 \%$ dapat dilihat pada Tabel 3.

Pada Tabel 3, dapat dilihat bahwa persentase anakan produktif tanaman padi tidak memperlihatkan perbedaan yang nyata sesama berbagai dosis kompos sampah kota. Hal ini diduga persentase anakan produktif adalah hasil perbandingan semua anakan menghasilkan malai dengan total anakan terbentuk di kali $100 \%$, dimana disini terjadi semua tanaman menghasilkan malai dan berbanding lurus dengan total anakan yang terbentuk mengakibatkan hasil persentase anakan produktif memperlihatkan perberbedaan yang tidak nyata karena pada penelitian ini menggunakan satu macam varietas padi gogo yaitu Situ Bagendit. Varietas menentukan lama pemunculan anakan dan jumlah anakan rumpun ${ }^{-1}$. Hasil temuan Defeng et al (2002) bahwa jumlah anakan produktif sangat dipengaruhi oleh varietas yang digunakan.

Tabel 3. Persentase anakan produktif / rumpun tanaman padi pada beberapa dosis kompos sampah kota umur 10 MST.

\begin{tabular}{cc}
\hline Dosis kompos sampah kota (t/ha) & Persentase anakan produktif $(\%)$ \\
\hline 0 & 77.33 \\
5 & 78.57 \\
10 & 79.08 \\
15 & 80.23 \\
20 & 81.72 \\
\hline
\end{tabular}

$\mathrm{KK}=2.69 \%$

Angka-angka pada kolom yang sama tidak ada diikuti oleh huruf kecil yang sama berbeda tidak nyata pada taraf nyata $5 \%$ menurut DNMRT. 


\section{d. Jumlah malai rumpun ${ }^{-1}$ (buah).}

Rata-rata jumlah malai per rumpun tanaman padi gogo setelah diuji lanjut DNMRT pada taraf nyata $5 \%$ dapat dilihat pada Tabel 4.

Pada Tabel 4, dapat dilihat bahwa bahwa jumlah malai padi gogo diberi berbagai dosis kompos sampah Kota tertinggi pada dosis 20 t/ha yaitu $13.44 \mathrm{~cm}$ yang tidak berbeda nyata dengan 15 t/ha dan berbeda nyata dengan 10,5 dan $0 \mathrm{t} / \mathrm{ha}$. Hal ini diduga berhubungan dengan semakin banyak kompos yang diberikan maka unsur hara semakin banyak tersedia sehingga jumlah malai pada dosis kompos sampah kota $20 \mathrm{t} / \mathrm{ha}$ paling banyak. Hal ini sesuai dengan hasil penelitian Gusnidar, Syafrimen, Burbay, Yusnaweti dan yulnafatmawita (2010) bahwa jumlah malai akan bertambah banyak seiring dengan meningkatnya dosis kompos tithonia yang diberikan pada padi sawah intensifikasi.

Tabel 4. Jumlah malai tanaman padi pada berbagai dosis kompos sampah kota umur 10 MST.

\begin{tabular}{|c|c|}
\hline Dosis kompos sampah kota (t/ha) & Jumlah malai/rumpun (buah) \\
\hline 0 & 10.67 \\
\hline 5 & 11.02 \\
\hline 10 & 11.71 \\
\hline 15 & 12.83 \\
\hline 20 & 13.44 \\
\hline
\end{tabular}

Angka-angka pada kolom yang sama tidak diikuti oleh huruf kecil yang sama berbeda tidak nyata pada taraf nyata $5 \%$ menurut DNMRT.

\section{e. Panjang malai (cm).}

Hasil Rata-rata panjang malai padi gogo setelah diuji lanjut DNMRT pada taraf nyata $5 \%$ dapat dilihat pada Tabel 5 .

Pada Tabel 5, dapat dilihat bahwa panjang malai tanaman padi tidak memperlihatkan perberbedaan antara dosis kompos sampah kota $0,5,10,15$ dan $20 \mathrm{t} / \mathrm{ha}$. Hal ini diduga karena pada kondisi lingkungan yang cukup menguntungkan seperti tersedianya air, hara dan cahaya matahari akan nmembuat pertumbuhan tanaman berlangsung normal, maka panjang malai yang terbentuk semata- mata ditentukan oleh faktor genetik yakni varietas tanaman. Pada percobaan ini menggunakan adalah sama yakni varietas Situ Bagendit, sehingga panjang malai yang dihasilkan relatif sama. Hal ini sesuai dengan pendapat Gadner, Pearce dan Mitchell (1991) bahwa tanaman dipengaruhi oleh genetiknya termasuk panjang malai. Selanjutnya Yusnaweti, Kasli, Eti Farda dan Reni Mayerni (2014) juga mendapatkan pada padi gogo varitas'Danau gaung panjang malai yang tidak berbeda nyata yang menggunakan berbagai jenis kompos.

Tabel 5. Panjang malai tanaman padi pada berbagai dosis kompos sampah kota umur 10 MST.

\begin{tabular}{cc}
\hline Dosis kompos sampah kota $(\mathrm{t} / \mathrm{ha})$ & Panjang malai $(\mathrm{cm})$ \\
\hline 0 & 19.63 \\
5 & 20.22 \\
10 & 21.41 \\
15 & 22.58 \\
20 & 23.76 \\
\hline
\end{tabular}

$\mathrm{KK}=2.72 \%$

Angka-angka pada kolom yang sama tidak ada diikuti oleh huruf kecil yang sama berbeda tidak nyata pada taraf nyata $5 \%$ menurut DNMRT. 


\section{e. Jumlah gabah malai ${ }^{-1}$ (butir).}

Rata-rata jumlah gabah per malai tanaman padi gogo setelah diuji lanjut DNMRT pada taraf nyata $5 \%$ dapat dilihat pada Tabel 6 .

Pada Tabel 6, dapat dilihat bahwa jumlah gabah per malai padi gogo yang diberi kompos sampah kota memperlihatkan perbedaaan yang nyata sesamanaya. Selanjutnya terhadap dosis kompos sampahkota 20 t/ha padi gogo memperlihatkan lebih tinggi yaitu 177.44 butir yang berbeda nyata dengan dosis kompos kota $15,10,5$ dan 0 t/ha. Hal ini diduga jumlah gabah per malai berasal dari jumlah malai dan panjang malai dan kenyataannya bahwa jumlah gabah per malai berkorelasi positif sangat nyata dengan jumlah malai dan panjang malai yang berarti jumlah malai dan panjang malai secara nyata sangat menentukan jumlah gabah per malai. Pada jumlah malai yang banyak dan panjang malai yang panjang akan menghasilkan jumlah gabah yang banyak. Hasil penelitian Agustamar (2007) kadar hara kompos tithonia $(\mathrm{B} . \mathrm{O}=50.49 \%$, C-org $=$ $29.28 \%, \mathrm{C} / \mathrm{N}=9.27, \mathrm{~N}=3.16 \%, \mathrm{P}=0.73 \%$, $\mathrm{K}=3.97 \%$ dan kadar air $=17.91 \%)$ sedangkan pada kompos Sapi (B.O $=35.45 \%$, $\mathrm{C}$-org $=20.56 \%, \mathrm{C} / \mathrm{N}=13.39, \mathrm{~N}=1.54 \%, \mathrm{P}$ $=0.43 \%, \mathrm{~K}=1.57 \%$ dan kadar air $=37.06$ \%). Hara yang cukup akan meningkatkan fotosintesis yang akan menghasilkan produksi bahan kering yang lebih banyak jumlah gabah per malai tanaman padi tidak memperlihatkan perberbedaan yang nyata sesamanya baik antara pengaruh berbagai dosis kompos.

Tabel 6. Jumlah gabah per malai tanaman padi pada berbagai dosis kompos sampah kota umur 10 MST.

\begin{tabular}{cccc}
\hline Dosis kompos sampah kota (t/ha) & Jumlah gabah per malai (butir) \\
\hline 0 & 114.46 & a & \\
5 & 120.32 & a & \\
10 & 122.54 & a & \\
15 & 145.88 & b & \\
20 & 177.44 & c & \\
\hline $\mathrm{KK}=21.68 \%$ & & &
\end{tabular}

Angka-angka pada kolom yang sama tidak diikuti oleh huruf kecil yang sama berbeda tidak nyata pada taraf nyata $5 \%$ menurut DNMRT.

\section{f. Bobot gabah rumpun $^{-1}(\mathrm{~g})$.}

Rata-rata bobot gabah rumpun ${ }^{-1}$ tanaman padi gogo setelah diuji lanjut DNMRT pada taraf nyata $5 \%$ dapat dilihat pada Tabel 7.

Pada Tabel 7, dapat dilihat bahwa bobot kering gabah per rumpun atau per ha tanaman padi memperlihatkan pemberian dosis kompos sampah kota 20 t/ha menunjukan bobot kering gabah per rumpun atau per ha lebih tinggi yang berbeda nyata dengan dosis $15,10,5$ dan 0 t/ha. Hal ini diduga hara yang tersedia lebih banyak sehingga mencukupi untuk pertumbuhan tanaman.

Penelitian Gusnidar (2007) pemberian tithonia $7.5 \mathrm{t}$ ha ${ }^{-1}$ pada padi sawah meningkatkan hasil gabah sebesar 20.51 $21.08 \mathrm{~g} \mathrm{pot}^{-1}(18.69$ - $19.21 \%)$. Hasil penelitian Yusnaweti (2016) pemberian kompos daun bambu 20 t/ha terhadap pertumbuhan padi gogo juga didapatkan hasil yang tertinggi. 
Tabel 7. Bobot gabah per rumpun tanaman padi pada beberapa dosis kompos sampah kota.

\begin{tabular}{ccccc}
\hline Dosis kompos sampah kota $(\mathrm{t} / \mathrm{ha})$ & Bobot kering gabah per rumpun $(\mathrm{g})$ & \multicolumn{2}{c}{$\mathrm{t} / \mathrm{ha}$} \\
\hline 0 & 10.24 & $\mathrm{a}$ & 2.57 & $\mathrm{a}$ \\
5 & 10.36 & $\mathrm{a}$ & 2.63 & $\mathrm{a}$ \\
10 & 11.21 & $\mathrm{a}$ & 2.79 & $\mathrm{a}$ \\
15 & 12.63 & $\mathrm{~b}$ & 3.41 & $\mathrm{~b}$ \\
20 & 15.67 & $\mathrm{c}$ & 3.99 & $\mathrm{c}$ \\
\hline
\end{tabular}

$\mathrm{KK}=11.74 \%$

Angka-angka pada kolom yang sama tidak diikuti oleh huruf kecil yang sama berbeda tidak nyata pada taraf nyata $5 \%$ menurut DNMRT.

\section{g. Bobot 1000 biji (g).}

Rata-rata bobot 1000 biji tanaman padi gogo setelah diuji lanjut DNMRT pada taraf nyata $5 \%$ dapat dilihat pada Tabel 8 .

Pada Tabel 8, dapat dilihat bahwa tanaman padi tidak memperlihatkan perberbedaan yang nyata sesamanya baik antara pengaruh berbagai dosis kompos antara $0,5,10,15$ dan 20 t/ha. Hal ini diduga karena menggunakan varietas yang sama yaitu verietas Situ Bagendit menunjukan tidak adanya perbedaan variasi jumlah sel dan ukuran sel biji, jadi disini lebih berperan sifat genetik dari tanaman, walaupun berbeda perlakuan tetapi perlakuan tersebut belum secara signifikan belum dapat merubah lingkungan tumbuh sehingga akan tetap memberikan bobot 1000 biji yang hampir sama. Didukung oleh Yusnaweti (2015) bobot 1000 biji pada padi gogo varietas Danau Gaung tidak berbeda nyata sesamanya, apabila pengaruh perlakuan tidak berbeda maka yang berperan adalah faktor genetik. Bobot 1000 biji yang menggunakan pupuk hijau Tithonia dan pupuk kandang dengan berbagai jarak tanam pada padi gogo varietas cantik juga memperlihatkan bobot 1000 biji yang tidak berbeda nyata (Bilman, 2008).

Tabel 8. Bobot 1000 biji tanaman padi pada berbagai disis kompos sampah kota .

\begin{tabular}{cc}
\hline Dosis kompos sampah kota (t/ha) & Bobot 1000 biji $(\mathrm{g})$ \\
\hline 0 & 26.42 \\
5 & 26.87 \\
10 & 27.28 \\
15 & 27.69 \\
20 & 27.72 \\
\hline
\end{tabular}

$\mathrm{KK}=2.41 \%$

Angka-angka pada kolom yang sama tidak ada diikuti oleh huruf kecil yang sama berbeda tidak nyata pada taraf nyata $5 \%$ menurut DNMRT.

\section{KESIMPULAN}

Berdasarkan dari hasil percobaan Respon Pertumbuhan dan Hasil Padi Gogo Terhadap Pemberian Beberapa Dosis Kompos Sampah Kota ternyata pemberian dosis 20 t/ha dapat memberikan pertumbuhan dan hasil yang terbaik pada tanaman padi gogo.

\section{DAFTAR PUSTAKA}

Agustamar. 2007. Kajian prospek penerapan Metode SRI (The System of Rice Intensification) pada sawah bukaan baru. Disertasi. Progam Pascasarjana. Univ. Andalas. Padang. 202 hal.

Agustamar, BS. Ahmad dan Y. Sondang. 2011. Rancangan Formulasi Organo 
Kompleks In-siu Untuk Perakitan Teknologi SRI (The System of Rice Intensification) pada sawah bukaan baru. Laporan Peneliian Hiber th I. Politeknik Pertanian Negeri Payakumbuh.

Badan Pusat Statistik. 2014. Statistik Indonesia. Badan Pusat Statistik. Jakarta.

Bilman. 2008. Modifikasi lingkungan melalui sistem penanaman serta penambahan bahan organik dan zat pengatur tumbuh dalam upaya peningkatan produktifitas padi gogo (Oryza sativa L.). Disertasi. Progam Pascasarjana. Univ. Andalas. Padang. 210 hal.

Defeng, Z., C. Shihua, Z. Yuping, and L. Xiaqing. 2002. Tillering patterns and the contribution of tillers to gain yield with hybrid rice and wide spacing. China National Rice Reasearch Institute, Hangzhou. CIIFAD, http://ciifad.cornell.edu/sri:ciifat@cor nell.edu. $125-131 \mathrm{p}$.

Gusnidar, Syafrimen, Burbey, Yusnaweti dan Yulnafatmawita. 2010. Pemberian Kompos Tithonia (Tithonia difersifolia) dan Jerami padi terhadap input pupuk buatan dan produksi padi sawah intensifikasi.
Yusnaweti. 2012. Pengaruh jenis dan dosis bahan organik terhadap pertumbuhan padi gogo pada Ultisol. Prosiding, Seminar Nasional, Pengembangan Agroindustri Untuk Mendukung Perekonomian Rakyat. Politeknik Pertanian Payakumbuh, November 2012

Yusnaweti. 2013. Respon Padi Gogo Terhadap Jenis Dan dosis Cendawan Mikoriza Arbuskula pada Ultisol. Joernal Menara Ilmu, Vol V no 38.

. Kasli, Eti Farda dan Reni Mayerni. 2014. Uji Beberapa Jenis Kompos yang yang tidak dan di beri Fungi MikorizaArbuskula Terhadap Pertumbuhan dan Produksi Padi Gogo di Lahan Marginal. Joernal Menara Ilmu, Vol III, no 45. . 2015. Response of Different Mycorrhizal Fungi and AdoptionSRI Mehode on The Growth And Production of Up land Rice. Seminar I ternational, Vietnam.

2016. On Growth Response and the Results of Upland Rice due to the Allotment of Some a Dose of Compost Bamboo Leaves Joernal Menara Ilmu, Vol X, jilid 2 no 73. 